\title{
A Survey of Shanghainese Dialect: Its Current Situation and Future
}

\author{
Tianao Guil and Yan Zhou² \\ ${ }^{1}$ Shanghai Foreign Language School, Hongkou District, Shanghai, China \\ 2University of California, Los Angeles, CA, USA
}

\section{$\underline{\text { ABSTRACT }}$}

Borge Udell, the founder of Wikitongues, questioned 'Would Cervantes have written the same stories had he been forced to write in a language other than Spanish? Would the music of Beyoncé be the same in a language other than English?' What he means is that every language carries a unique culture and represents a group of people. All languages and dialects are worth appreciation and preservation. Shanghainese dialect is no exception. As a native Shanghainese citizen, I believe that it is high time that we should be aware of the importance of preserving and inheriting this dialect. To achieve this goal, research about the current situation is indispensable. Therefore, I researched the current situation of Shanghainese and implicated some possible methods to protect this dialect.

\section{Introduction of the current situation of world languages}

Currently, there are 7117 (data updated on March 28, 2020) languages in the world (https://www.ethnologue.com). According to linguist David Crystal (2008), around every 14 days, a language dies (Crytal 2008). What's more, around $40 \%$ of all languages are endangered, meaning that they are spoken by less than 1000 people. Some have recognized the severe situation and have taken action. For example, Wikitongues, a well-known non-profit organization aiming at endangered language protection, is now powered by over 1,000 people on every continent. Bogre Udell, the founder of this organization said in an interview with National Geographic that 'When humanity loses a language, we also lose the potential for greater diversity in art, music, literature, and oral traditions.'

According to UNESCO, more than 300 languages are spoken in China, and the dominant one is Mandarin (or Putonghua, 'common speech'); regional dialects and other languages in China have been threatened by Putonghua since it was being rigorously promoted across the country due to the Law of Common Language of PRC carried out in 2001 (中华人民共和国国家通用语言文字法). As shown on the official website of UNESCO, about 144 languages are endangered, which is nearly half of all Chinese languages. The situation is no doubt very severe, and the government has taken some action. For example, in Tibet, various levels of government have tried to expand the Tibetan language into digital realms, creating e-readers, smartphones, and electronic dictionaries (Hinton, Huss, \& Roche, 2018). While some policies work for many endangered languages, there are no or very few protections for dialects that still have a large number of speakers but are potentially threatened.

\section{Introduction of Shanghainese dialect}

Shanghainese dialect (or Shanghainese for short), one of the $\mathrm{Wu}$ dialects, is mainly spoken in Shanghai. Due to the pouring in of people outside the city and some recent Mandarin promotion policies by the government, the population of Shanghainese speakers is decreasing. The results of a survey conducted in 2013 by the Shanghai Statistics Bureau 
have shown that, among citizens older than 13 , there are $16 \%$ fewer people who can speak Shanghainese than those who speak Mandarin.

According to previous studies, the decrease in the Shanghainese-speaking population might be caused by two reasons. The first reason is Mandarin promotion policies Qian Nairong, a linguist in Shanghainese research believes this is the major reason for the Shanghainese decline. A 37-year-old Shanghai resident recalled in one of my interviews that Shanghainese was completely banned in all Shanghai schools in the late 1980s, and was even forbidden to be spoken during breaks. According to the Critical Period Hypothesis, the capacity to learn is shaped by genes that open and close a critical window when learning can take place, so if children are not exposed to spoken language during this critical period, they will always struggle with speech. This caused many children at that time to lose the opportunities to learn Shanghainese during the critical period (Fineburg \& Myer, 2014). According to the results of my survey, $72.41 \%$ of all respondents agree that Mandarin promotion is the main cause. Meanwhile, during the early $1990 \mathrm{~s}$, with the development and opening of Shanghai, especially Pudong (a district of the big Shanghai area), a large number of migrants from other provinces moved to the city. The number of people speaking Mandarin and different dialects increased rapidly. Since then, although Shanghai's economy has been greatly stimulated, the position of the local dialect was threatened.

It is self-evident that Shanghainese, as a dialect of Chinese, represents Shanghai and its citizens. The uniqueness of Shanghainese is that it contains not only local features but foreign elements as well. Some words only exist in Shanghainese, showing Shanghainese citizens' lifestyles, moods, and diverse artistic interests, improving their sense of belonging and identity. Apart from this, Since the beginning of the $20^{\text {th }}$ century, Shanghai has been accepting more and more foreign cultures and now it has become an international metropolis. In Shanghainese, lots of words are affected by English transliteration. For example, the transliteration of 'gander' is very often used to describe a fool or idiot; and the transliteration of 'colour' describes people who wear colourfully whose extended meaning is fashionable. This phenomenon reflects the history that lots of foreign businesspeople poured in around a century ago. So, it is of vital importance to make effort to preserve the Shanghainese dialect.

Given the situation that Shanghainese dialect and many other dialects are gradually disappearing in China, and realising the importance of well protecting them, the government has made policies and efforts before as protections. In 2008, the Chinese Language Resource Audio Database was established. On May 14, 2015, the Ministry of Education and the National Language Commission announced the launch of the National Language Resources Protection Project (Fan Junjun, 2018). Shanghainese recordings are included in this database. Besides, Shanghainese is used to announce station names in public transportation. In order to increase the domains of Shanghainese dialect, there are also about seven or eight television programs and several radio programs in Shanghainese. Many people have encouraged to offer Shanghainese classes in kindergartens and elementary schools, but few schools teach Shanghainese. Those who do offer Shanghainese are simply teaching it as an extracurricular activity. According to a news report in Shanghai Youth Paper in 2014, Shanghainese teaching is extremely hard because some young teachers are not able to speak well themselves and teaching materials are hard to choose.

However, I noticed that there is little research about the current situation of Shanghainese usage. There have been discussions about this, but many reports and papers are out of date. This paper aims to conduct a deeper analysis of the current situation and to propose some possible measures to protect Shanghainese accordingly. Moreover, since similar phenomena that the number of regional dialects speakers are decreasing occur in other parts of China and other countries, I hope this paper could be valuable for the research and protection of other languages and dialects. According to a UNESCO document entitled Language vitality and endangerment, nine factors are listed in language vitality. Among them, the first and most crucial one is intergenerational language transmission (Grenoble, \& Whaley, 2006), which refers to the movement of a language between one generation and another. Since this is important, I hope to find out the Shanghainese usage among teenagers under 18, who will be parents in the future. If many of them are not able to speak Shanghainese, their children will grow up in an environment without Shanghainese. 


\section{Methodology}

The data of this study were collected in two ways. The first one is an online survey sent out through WeChat, the biggest social media application in China, which allows me to get a large number of respondents quite conveniently. Online surveys, in particular, have a very small cost per respondent. Also, the anonymity of surveys allows respondents to answer with more candid and valid answers. This survey enables me to collect relatively massive and valid data about Shanghainese citizens' usage of Shanghainese dialect and attitudes towards this language. The survey consists of 27 questions in total, including 25 single-choice questions and 2 multiple-choice questions. The survey questions include the respondents' Shanghainese proficiency levels, their daily usage of Shanghainese, people's attitudes towards Shanghainese protection, and their knowledge about existing Shanghainese protection policies. The language of the whole survey is Mandarin Chinese. At last, 203 respondents answered this survey, and all the responses are valid. The respondents are all local residents, and most (81.28\%) of them were born in Shanghai. There are respondents from various age levels, among which 46 are teenagers under 18. I will focus on this particular age group as the focus of my analysis. The gender distribution of respondents is 68 respondents male and 135 female.

Another part of my data is interviews with 6 residents about their attitudes and knowledge about Shanghainese protection policies, which are used for qualitative analysis. Questions in my interview are similar to those in the survey, but most are open-ended questions so that interviewees can elaborate on their answers.

\section{Findings}

In this part of the paper, I will present my findings of Shanghai residents' proficiency level of Shanghainese, the frequency of Shanghainese usage in daily lives, local residents' attitudes towards Shanghainese protection, and their knowledge about actions of Shanghainese revitalization.

1. What are Shanghai residents' proficiency level of Shanghainese?

I divide different Shanghainese proficiency levels into four:

Level 1: master

Level 2: can speak, but not native level

Level 3: can understand but are not able to speak

Level 4: do not understand at all

Among the 203 respondents, 46 are teenagers under 18, which occupies $22.66 \%$ of all. In Figure 1, blue represents Level 1, dark green represents Level 2, yellow represents Level 3, and red represents Level 4. In terms of people under 18: 26.09\% are in Level 1, 26.09\% are in Level 2, 39.13\% are in Level 3, and 8.7\% of respondents are in Level 4. These numbers show that teenagers not able to speak Shanghainese account for the largest proportion. If we make a comparison between the data of teenagers with the data of the elders, it would be more direct. For respondents older than 30, people who can master Shanghainese (Level 1) form more than $60 \%$ of all. Only half of the young people between 18 and 29 can reach the same level of proficiency. Shockingly, only 12 out of 46 minors are at this level. 


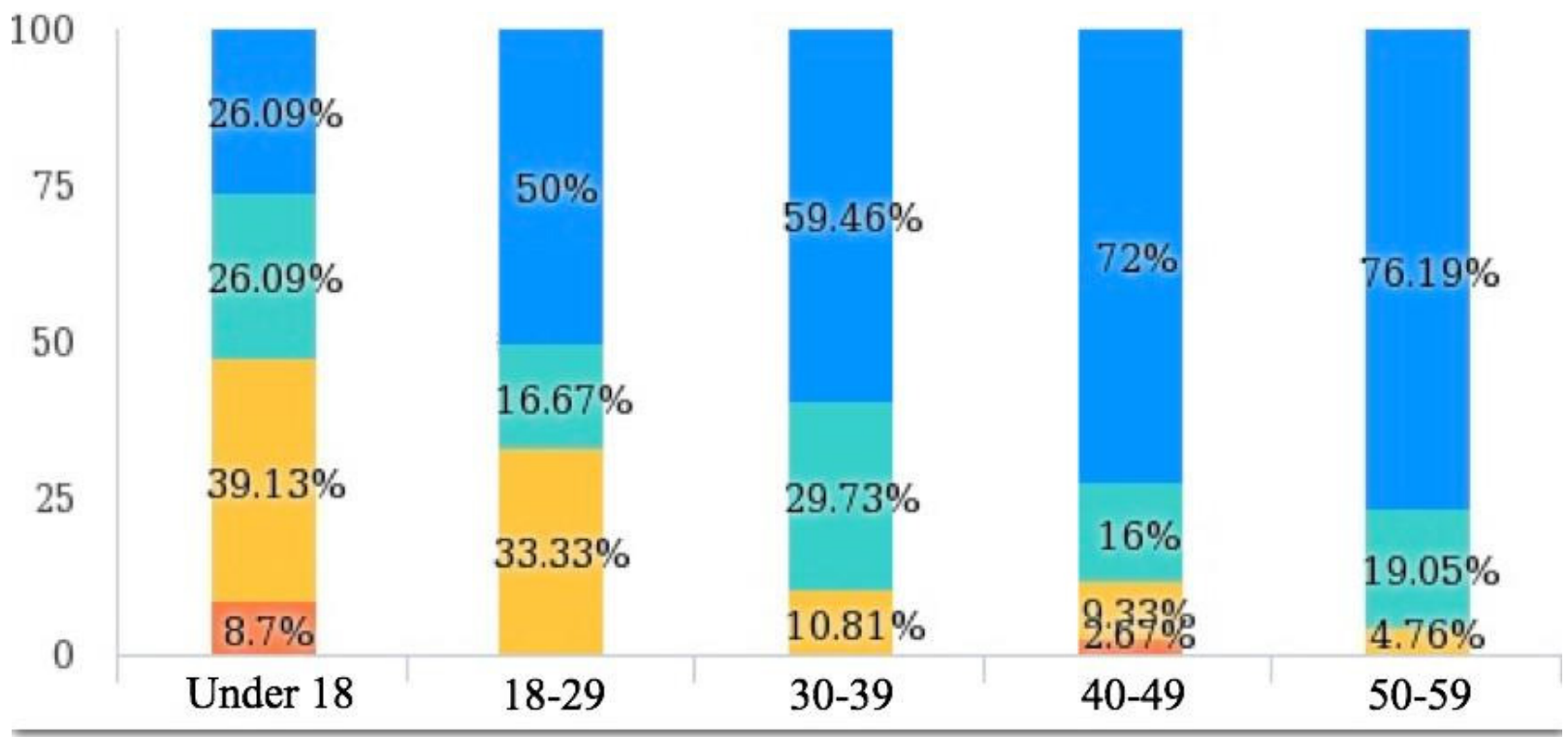

Figure 1. This chart shows the answers on Shanghainese mastery from five age levels: under 18, 18-29, 30-39, 4049, and 50-59. Each proficiency level has a colour. Blue represents Level 1, dark green represents Level 2, yellow represents Level 3, and red represents Level 4. The percentages for each proficiency level are marked.

We can see that the number of people who can master Shanghainese is declining with the decrease of age, and the speed of this decline is more rapid at young ages. It is worth noticing that, the number is halved when moving from people between 18-29 to under 18, which is a sharp decrease. What's more, the number of people who can understand but are not able to speak and those who totally cannot speak Shanghainese are the highest among people under 18 respectively. The data directly shows that Shanghainese mastery among minors is worrying, and intergenerational language transmission is not accomplished well at all. Since teenagers in Levels 3 and 4 cannot speak themselves, we can reasonably speculate that they will not be able to transmit Shanghainese to their children. If we estimate based on this, then almost half $(39.13 \%+8.7 \%)$ of future families in ten or twenty years would not use Shanghainese at all.

2 How frequently is Shanghainese spoken in everyday life?

What causes so many Shanghainese teenagers disable to speak their local dialect? In the survey, 50\% of respondents under 18 use Mandarin with their older family members, while only $21.74 \%$ use Shanghainese dialect, which is much lower than other age levels.

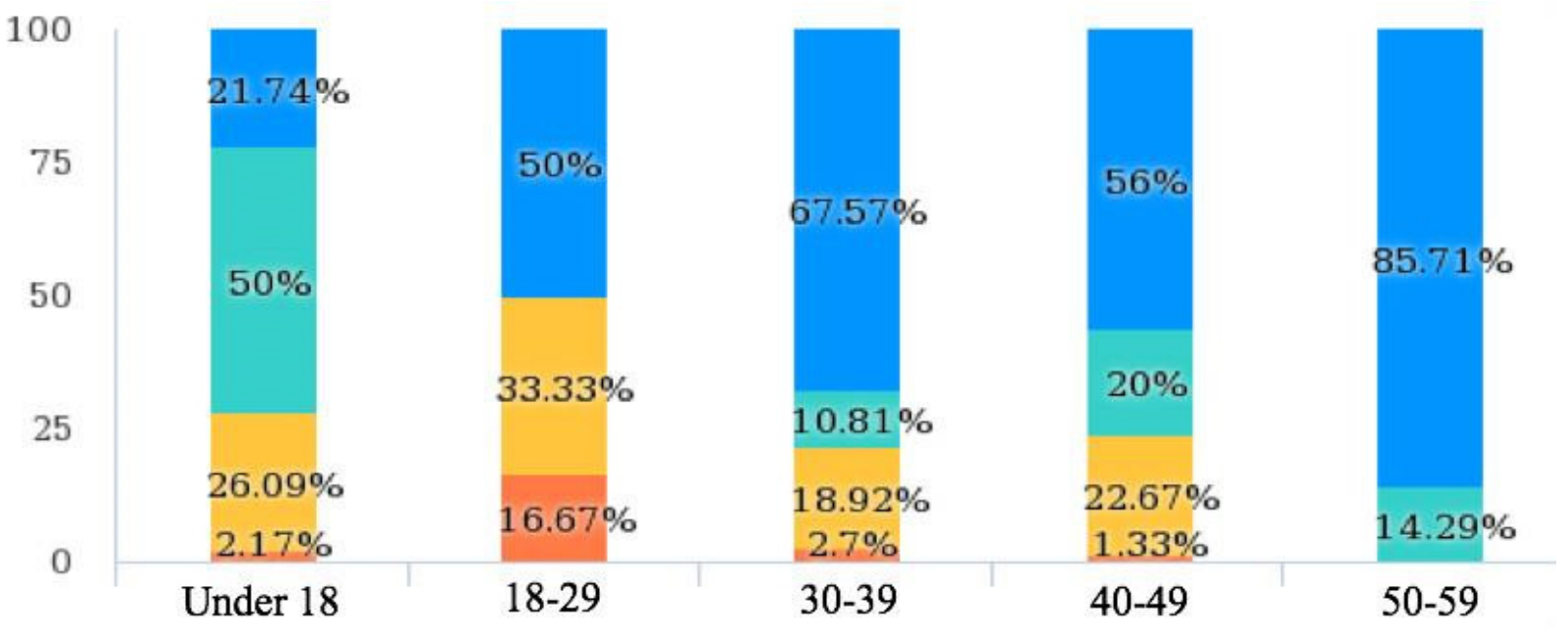


Figure 2. This chart shows which dialect people from five age levels use with their older family members. Blue represents Shanghainese, dark green represents Mandarin, yellow represents using different dialects according to different occasions, and red represents other dialects.

Figure 2 clearly shows the pathetic reality: very few teenagers use Shanghainese. I believe that not using this dialect when growing up is the main direct reason why many of them cannot speak it. Two senior high students in my interview admit that they never use Shanghainese with their parents, although they can totally understand Shanghainese. Another senior high student who masters Shanghainese stated during the interview that, 'I always use Shanghainese at home, with my family, and with my relatives. I will definitely teach Shanghainese to my children, no matter others still speak it or not. I don't want to see this language disappear.' It is satisfying, but teenagers like him only account for $21.74 \%$ of all teenagers. The situation is not optimistic at all.

To find out how frequently Shanghainese is spoken in different domains, I asked a multiple-choice question: On which occasions do you use Shanghainese? The choices provided in the survey include working places or school, with family, with friends, with strangers, and when talking to him or herself.

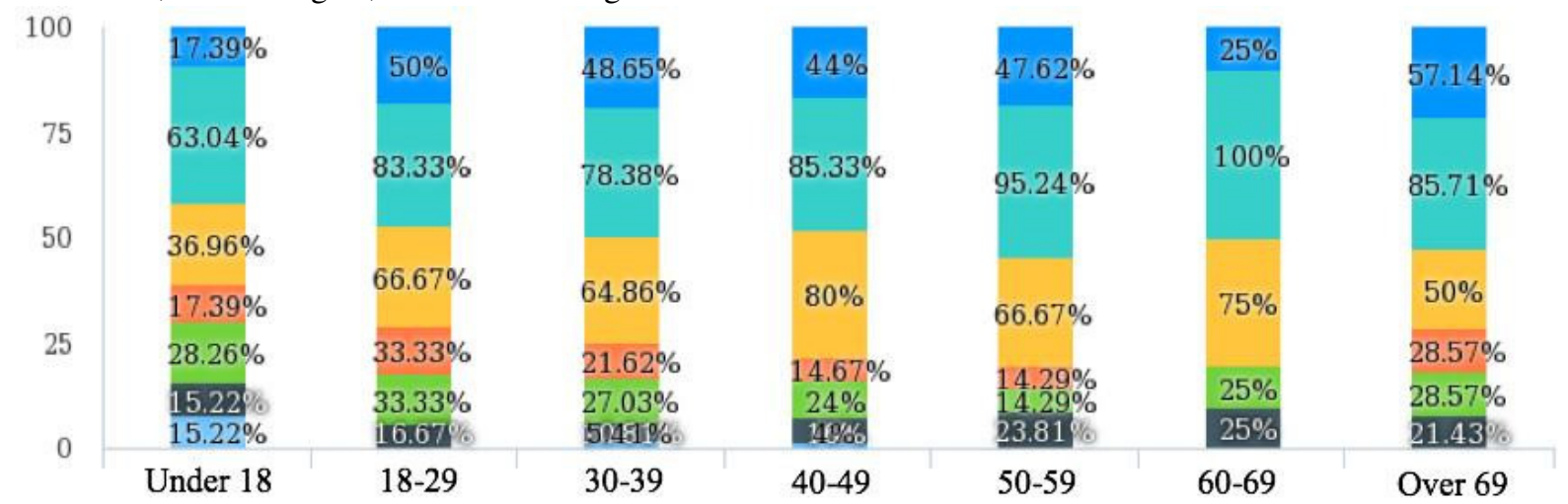

Figure 3. This chart shows how frequently Shanghainese is spoken in different domains by people from seven age levels. Blue represents working places or school, dark green represents family, yellow represents friends, red represents strangers, light green represents when talking to themselves, black represents on other occasions, and light blue represents almost or completely never using Shanghainese.

It is easy to find out that at all age levels, most people use Shanghainese at home with families. As mentioned in my introduction, the influx of migrants might be one reason to cause the decline of Shanghainese usage and the increase of Mandarin usage in public places. But this influx does not have any impacts on people's preference on those private and informal occasions, including in families and among friends, where Shanghainese is still used quite often. Therefore, family occasions are probably one of the essential elements to promote the protection of the Shanghainese dialect.

3 What are people's attitudes towards Shanghainese protection?

In the question 'Do you think that Shanghainese should be inherited?', almost all respondents give the same answer: YES. 


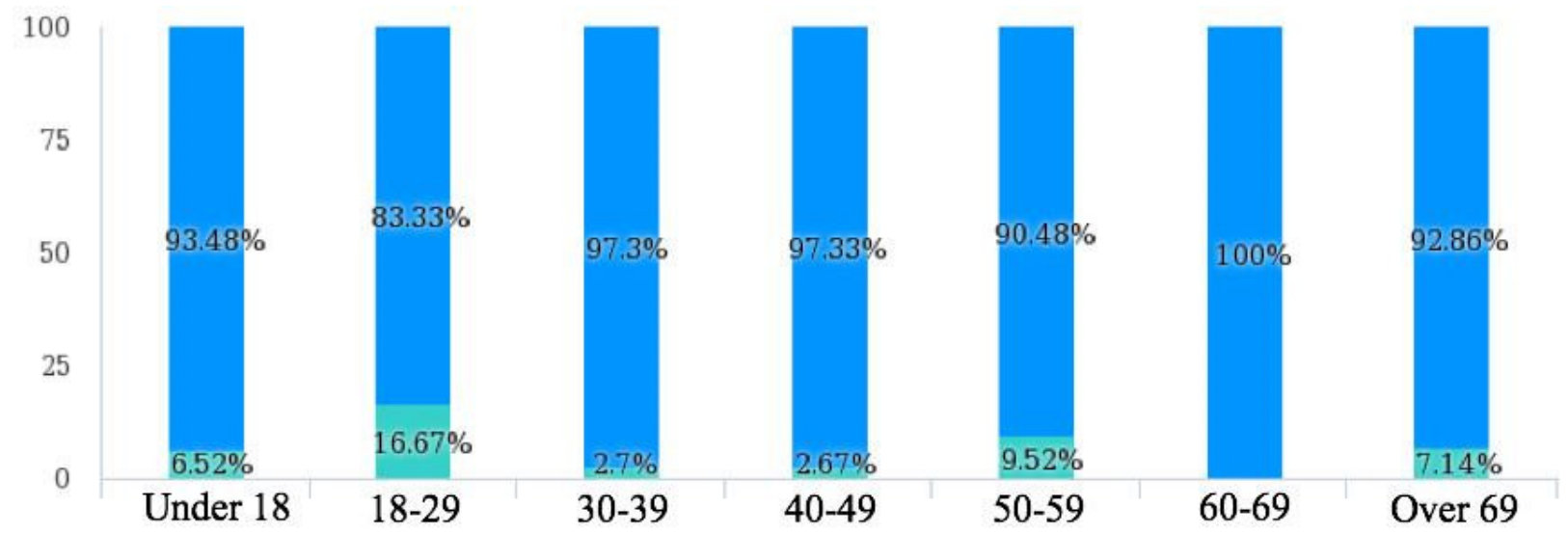

Figure 4. This chart shows the percentage of respondents who say yes to the question 'Do you think that Shanghainese should be inherited?' and those who say no. Blue represents yes, and dark green represents no.

When talking about the reasons, the word "culture" is often mentioned. $87.06 \%$ of people believe that culture cannot live itself without a symbolic language and that Shanghainese can represent Shanghai culture and history. $49.75 \%$ of the respondents think that a Shanghainese citizen should be able to speak the Shanghainese dialect. Some also state that this dialect can help people feel closer and warmer. Interestingly, some even say that it is more convenient and comfortable to say curse words to outsiders. The result also shows that very few citizens object to Shanghainese protection: some think that Mandarin and other languages should be used more because Shanghai is an international metropolis. A 16-year-old student insists that a multilingual environment is not efficient in communication, which is related to pragmatism. The same as most people, I still believe that it is necessary to protect and inherit Shanghainese. Every language and dialect carries a unique culture. As part of the Shanghai local culture, the Shanghainese dialect should be well protected. People who are in objection have lost the agreement to language and cultural diversity, which reflects an even more severe crisis.

Although most respondents say 'We need to protect Shanghainese', few people are taking actual actions. Though $93.48 \%$ of teenagers in my survey think that it is necessary to inherit and protect Shanghainese, only around half $(26.09 \%+26.09 \%$, people in Levels 1 and 2$)$ can speak it and $21.74 \%$ speak it with their older family members. In the interview with two 15-year-old teenagers, they both believe that Shanghainese should be well protected, but they seldom speak it. This is a contradiction. This could be explained by the little attention paid to Shanghainese revitalization now. The fewer teenagers can speak it, the sooner Shanghainese would disappear. So what should be done is to help and encourage teenagers to speak more Shanghainese.

4 What do people know about the actions of Shanghainese revitalization?

Language policies have a big impact on the development of languages. Several decades ago, Shanghainese was almost the only dialect spoken among citizens in Shanghai. But due to some Mandarin promotion policies, mainly the Law of Common Language, Mandarin is gradually becoming more dominant in China. In recent years, the Shanghainese government has also made some Shanghainese protection policies. In this section, I will present the survey result of people's knowledge about the two types of policies (Mandarin promotion and Shanghainese revitalization)

Based on the results of the survey, $60.87 \%$ of respondents under 18 have never heard of any Mandarin promotion policies before. However, only $43.31 \%$ of people over 18 do not know them. This is mainly because those policies have already made effects, and minors grow up mostly in a Mandarin environment. They may think it natural to use Mandarin under most circumstances. Thus, in terms of Mandarin promotion, the Chinese government has done pretty well. On the contrary, people between 40-49 can feel the difference. Before, they spoke Shanghainese with their friends, families, and strangers. But now, they have to speak Mandarin with most strangers and many colleagues. Mandarin promotion policies might be a reason why Shanghainese is used less frequently. 
And what about Shanghainese protection policies? A main such policy is the Chinese Language Resources Audio Database, where preserves Shanghainese audio records. Do people in Shanghai know that? The answers are similar among all respondents. $66.01 \%$ of respondents have not heard of any Shanghainese protection policies at all. What's more, I didn't discover any other official Shanghainese protection policies, so Shanghainese protection is not on the government's main agenda.

Although there are few official Shanghainese protection policies from the government, some actions have been taken by other parties. There are at least 7 TV programs broadcast shown in Shanghainese. Shanghainese TV series like Happy Apartment (Kaixin Gongyu in Chinese) and Black Tea House (Hongchafang in Chinese) were very popular among citizens. Other than these, there are radio channels like Shanghai drama and music radio and Shanghai story radio contains programs presented in Shanghainese. $85.22 \%$ of all respondents believe that they help Shanghainese revitalization. 82.27\% think it useful to announce station names in Shanghainese on buses. It is pleasing to see that effective efforts are being made, but overall, both the national government and the municipal have not been aware of the severity of the decreasing population of Shanghainese speakers and the importance of protecting this dialect. To maintain the diversity of languages and cultures in China, we need to pay much more attention and take more measures to Shanghainese revitalization and protection.

In summary, the current situation of the Shanghainese dialect is not optimistic. Only a small number of people younger than 18 can speak Shanghainese and use it in their daily lives. This is mainly caused by Mandarin promotion policies and the influx of migrants in recent years. Although most people think it necessary to inherit Shanghainese, actual actions are not enough. I call for all Shanghainese citizens to be aware of the severity of the situation and pay more attention to it.

\section{Implications and Conclusion}

Based on previous research and the findings of my study, Shanghainese now is in a very dangerous position. Teenagers are using less Shanghainese, and it is being used in fewer domains. According to the estimation mentioned before, around half of the children will not be able to speak Shanghainese in one or two decades. Noting the importance of language and cultural diversity, I believe that actions should be taken to help protect Shanghainese. Here I propose several suggestions as a reference and my recommendations are on three different levels: government, schools, and communities.

Firstly, it would be effective if the government make some policies. For instance, I propose that the government should try to encourage educational institutions to offer a regular Shanghainese curriculum. The government could implement more Shanghainese usage in public, such as public transportation, weather forecasts, shopping malls, tourist attractions, and so on.

Secondly, schools should encourage children to speak Shanghainese. According to the Critical Period Hypothesis mentioned in my introduction (Fineburg \&Myer, 2014), it would be effective if teenagers start to speak Shanghainese in schools when they are still young. Schools, especially elementary schools, could set Shanghainese lessons. Audio and video recordings could be used as teaching materials. Even if it is too difficult to set Shanghainese as formal courses, it is still possible for schools to offer Shanghainese as an extracurricular activity, such as Shanghainese rhymes and knowledge contests about Shanghainese. In addition, schools can provide related resources for students, for example, books about local culture, Shanghainese promotion lectures, and cultural festivals. In this case, schools can still cultivate the interest of Shanghainese in students' hearts. Looking back to the teenagers who don't think it necessary to inherit Shanghainese, I believe that it is also urgent to let people notice the importance of language and cultural variety in this way.

At last, some things could be done by communities. Shanghai communities should hold promotional activities regularly in community service centres. For example, they can invite local people to share their stories about old Shanghai and its culture. They can hold Shanghainese reading contests. They can organize residents to take part in 
short sketches and sing Shanghainese songs. Meanwhile, community staff could encourage families to speak more Shanghainese at home, particularly with children, by posting publicizing posters and holding activities mentioned above. If children speak more Shanghainese at home, they can have more chances to practice and become easier to speak Shanghainese proficiently and fluently.

In the end, I hope that more people start to realise and appreciate the meaning of the Shanghainese dialect. This dialect symbolises Shanghai culture and is part of Shanghai culture. A city without its indigenous culture cannot become the centre of world cultures. All in all, Shanghainese is no doubt part of Shanghai culture that reflects the uniqueness and attractiveness of this huge and inclusive city. I sincerely wish that all Shanghainese citizens could speak Shanghainese, could be very proud of their Shanghainese identity, and could feel a warm sense whenever they heard Shanghainese far from home...

\section{Acknowledgments}

I am sincerely grateful to everyone who has helped me with this paper. It is my advisor Yan Zhou that taught me how to conduct a research and design a survey scientifically. Without her help I wouldn't even know how to write this paper. I also appreciate all the respondents who participated in my survey. The data collected have been extremely crucial for the completion of this project.

\section{References}

2013 Shanghai Municipality's Language Application Ability Survey Report 【2013年上海市民语言应用能力调查 报告】Retrieved from http://tjj.sh.gov.cn/html/fxbg/201402/266714.html

4 Main Benefits of Survey Research. Retrieved from https://www.snapsurveys.com/blog/4-main-benefits-surveyresearch/

Crystal, D. (2008). Hook or by Crook: A Journey in Search of English

Difficulties in developing Shanghai dialect in some schools in Shanghai 【沪上部分学校开展上海话教学仍存在

困难】 Retrieved from http://app.why.com.cn/epaper/qnb/html/2014-04/14/content_199171.htm?div=-1

Fan, J. (2018). The Preservation and Protection of Endangered Languages in China

Fineburg, A. \& Myer, D. (2014). Myer's Psychology for AP

Grenoble, L., \& Whaley, L. (2006). Saving languages: An introduction to language revitalization

Hinton, L., Huss, L., \& Roche, G. (2018). The Routledge Handbook of Language Revitalization

Language Death. Retrieved from https://www.thoughtco.com/what-is-language-death-1691215

Languages of the world. Retrieved from https://www.ethnologue.com 
Qian Nairong: The inheritance of Shanghai dialects, the key is to let the new generation speak Shanghai dialect 【钱 乃荣：上海方言的传承，关键要让新生代们讲上海话】Retrieved from https://www.shobserver.com/news/detail?id=31808

Research Methods Guide: Interview Research. Retrieved from https://guides.lib.vt.edu/researchmethods/interviews

The Race to Save the World's Disappearing Languages. Retrieved from https://www.nationalgeographic.com/news/2018/04/saving-dying-disappearing-languages-wikitongues-culture/

UNESCO Atlas of the World's Languages in Danger. Retrieved from http://www.unesco.org/languages-atlas/ 